\title{
Clinical use of azelnidipine in the treatment of hypertension in Chinese patients
}

\author{
This article was published in the following Dove Press journal: \\ Therapeutics and Clinical Risk Management \\ 24 February 2015 \\ Number of times this article has been viewed
}

\author{
Bi-Lian Chen ${ }^{1, *}$ \\ Yin-Zhuang Zhangl,* \\ Jian-Quan Luo 2,3 \\ Wei Zhang ${ }^{2,3}$ \\ 'Department of Geriatrics, Xiangya \\ Hospital, Central South University, \\ Changsha, Hunan, People's Republic \\ of China; ${ }^{2}$ Department of Clinical \\ Pharmacology, Xiangya Hospital, \\ Central South University, Changsha, \\ Hunan, People's Republic of China; \\ ${ }^{3}$ Institute of Clinical Pharmacology, \\ Central South University, Changsha, \\ Hunan, People's Republic of China \\ *These authors contributed equally to \\ this work
}

Background: Hypertension is the most common chronic disease and the calcium channel antagonist is the most popularly used antihypertensive drug in Chinese patients. Azelnidipine is a third generation and long-acting dihydropyridine calcium channel antagonist. A series of research has demonstrated that azelnidipine produced an effective antihypertensive effect in patients with essential hypertension. Now it is need to summarize clinical use of azelnidipine in the treatment of hypertension in Chinese patients.

Methods: Relevant literature was identified by performing searches in PubMed and CNKI (China National Knowledge Infrastructure), covering the period from January 2003 (the year azelnidipine was launched) to July 2014. We included studies that described pharmacology of azelnidipine, especially the pharmacokinetics, clinical efficacy, and safety and tolerability of azelnidipine in a Chinese population. The full text of each article was strictly reviewed, and data interpretation was performed.

Results: In Chinese healthy volunteers, a single-dose oral administration of azelnidipine 8-16 mg had a peak plasma concentration of $1.66-23.06 \mathrm{ng} / \mathrm{mL}$ and time to peak plasma concentration was 2.6-4.0 hours and the area under the plasma concentration versus time curve from time 0 hour to 96 hours was $17.9-429 \mathrm{ng} / \mathrm{mL} \cdot \mathrm{h}$ and elimination half-life was 16.0-28.0 hours. A number of clinical trials have demonstrated that azelnidipine produced a significant reduction in blood pressure in Chinese patients with mild-to-moderate hypertension, which was similar to that of other effective antihypertensive drugs such as amlodipine, zofenopril, and nifedipine. In addition to its antihypertensive effect, azelnidipine had other cardiovascular protective effects as well, like anti-oxidative action, decreasing heart rate, and improving systolic and diastolic function. Azelnidipine was generally well tolerated in Chinese patients and no severe adverse events were observed.

Conclusion: Azelnidipine is effective and safe in the treatment of hypertension in Chinese patients.

Keywords: azelnidipine, hypertension, Chinese, pharmacology, pharmacokinetics, efficacy

\section{Introduction to the management issues in the treatment of hypertension in Chinese patients}

Hypertension is the most common chronic disease in the People's Republic of China and a major risk factor for cardiovascular disease, stroke, and kidney disease. The mortality rate of stroke is the major complication of hypertension in Chinese patients. The 2010 Chinese guideline for the management of hypertension is an update of the previous ones in 1999 and 2005, and it has covered blood pressure (BP) measurement, diagnosis, epidemiologic studies, assessment of risk factors, BP monitoring, management of lifestyle, and drug therapy. ${ }^{1}$

The prevalence of hypertension had been investigated in the People's Republic of China in the years 1958, 1979, 1991, and 2002, especially the last one based
Correspondence: Wei Zhang

Department of Clinical Pharmacology, Xiangya Hospital, Central South University, Changsha, Hunan 410008, People's Republic of China Tel +86 73I 84805380

Email yjsd2003@।63.com 
on the diagnosis of hypertension according to World Health Organization and International Society of Hypertension: when a person's systolic blood pressure(SBP) is $\geq 140 \mathrm{mmHg}$ or diastolic blood pressure (DBP) $\geq 90 \mathrm{mmHg}$, or both, on repeated examinations without any anti-hypertensive drug. ${ }^{1}$ These standards apply to all adults older than 18 years of age. It was investigated and found that in 2002, nearly 1.6 billion Chinese adults (aged $\geq 18$ years), about one fifth of adults, had high BP. Compared with 1991, the prevalence was increased by $31 \%$. The awareness rate was $30.2 \%$ and the drug treatment rate $24.7 \%$ and control rate $6.1 \%$. About $90 \%$ of adults with high BP have primary hypertension, sometimes called essential hypertension. The cause of primary hypertension is not known clearly. Most patients with hypertension have other risk factors as well, including lipid abnormalities, glucose intolerance or diabetes, a family history of early cardiovascular events, obesity, and cigarette smoking, and so on.

The importance of ambulatory BP monitoring (ABPM) and home BP monitoring (HBPM) for the diagnosis and monitoring of hypertension has been recognized and emphasized for a period of time. BP measure at a Doctor's office is usually higher than ABPM and HBPM. It is recommended that the ABPM and HBPM be used for the diagnosis of isolated office (white coat) hypertension and isolated ambulatory (masked) hypertension.

As hypertension is recognized as a "cardiovascular syndrome", the management strategy should be based on the overall risk of cardiovascular disease estimated with all related risk factors, target organ damage, and co-morbidity of patients. The goal of treating hypertension is set at $\mathrm{SBP} / \mathrm{DBP}<140 / 90 \mathrm{mmHg}$ in uncomplicated hypertension; $<150 / 90 \mathrm{mmHg}$ for the elderly ( $\geq 65$ years old), or if tolerable, $<140 / 90 \mathrm{mmHg}$; and $<130 / 80 \mathrm{mmHg}$ for those with diabetes, coronary heart disease, or renal disease. ${ }^{2-7}$ In general, hypertension is also a "lifestyle disease". So, such lifestyle modifications as limiting salt intake to $6 \mathrm{~g} / \mathrm{d}$, lowering body mass index to $25 \mathrm{~kg} / \mathrm{m}^{2}$, smoking cessation, moderation of alcohol consumption, increasing dietary potassium intake, and physical activity, should be implemented for the prevention and control of hypertension. Several hypertensive populations need special attention in the prevention and control of hypertension, such as children and adolescents, the elderly, pregnant women, and patients with various cardiovascular complications. At the same time, it is important to detect and treat secondary hypertension.
Since most patients with hypertension are treated by primary care physicians, it is recognized that strengthening the education and standardized management of hypertension in the community, such as measuring BP at regular intervals, and rational use of drugs, is the basic way to increase the awareness rate and the drug treatment rate and control rate of hypertension.

With regard to the choice of antihypertensive drugs, the 2010 guideline in the People's Republic of China confirms that a calcium channel antagonist (CCB), diuretic, $\beta$-receptor blocker, angiotensin-converting enzyme inhibitor, and angiotensin II receptor blocker are all suitable for use as mono-therapy, and in some combinations with each other. ${ }^{1}$ A single pill containing these drugs can be administered as initial and maintenance antihypertensive treatment. Selection of the optimal therapy regimen should be based on a person's individual demographics, BP, cardiovascular risk, co-morbidities, and preference, as well as evidence for preferential beyond-BP-lowering benefits of different antihypertensive agents. The basic principles of drug treatment are a low dosage, priority of long-period drug, a combination of drugs, and individualized therapy. Among these drugs, dihydropyridine CCBs have no absolute contraindications for use and are a preferred drug in mono-therapy and in combination with other agent classes in many Chinese patients.

CCBs, including non-dihydropyridine and dihydropyridine CCB (DHP-CCB), block the calcium channel on vascular smooth cells to dilate the blood vessels to lower the BP. CCB is often used in combination with other agents, especially for elderly hypertensive patients, systolic hypertension, accompanied by stable angina, coronary and carotid atherosclerosis. There are about ten dihydropyridine CCBs used in Chinese patients with hypertension, among which azelnidipine is a new drug.

\section{Methods}

Papers on the topic of azelnidipine published online between January 2003 (the year azelnidipine was launched) and July 2014 were retrieved from PubMed and CNKI (China National Knowledge Infrastructure) using the search terms "azelnidipine", "pharmacology", "pharmacokinetics", "efficacy", "safety", "hypertension", and "Chinese" in English for the PubMed database and in the Chinese language for the CNKI database. Fifty-four articles were identified. The inclusion criteria included studies that described pharmacology of azelnidipine, especially the pharmacokinetics, clinical efficacy, and safety and tolerability of azelnidipine in the Chinese population. Exclusion criteria consisted of: duplications, not 
useful to answer literature review questions after reading the title and the abstract, Chinese review, data being incomplete, and papers with no references. Twenty-three articles were finally included under this search strategy and inclusion/ exclusion criteria (Figure 1). The full text of each article was strictly reviewed, and valuable information was summarized by interpretation of the data.

\section{Pharmacology, mode of action, pharmacokinetics of azelnidipine}

Azelnidipine, (( \pm )-(3)-(1-diphenylmethylazetidin-3-yl)-5-isopropyl-2-amino-1,4-dihydro-6-methyl-4-(3-nitrophenyl)3,5-pyridinedicarboxylate; CS-905), is a third generation, long-acting dihydropyridine calcium antagonist. Azelnidipine was jointly developed by Ube Industries, Ltd. (Yamaguchi, Japan) and Daiichi Sankyo Co, Ltd (Tokyo, Japan) and launched into the market as Calblock in Japan in $2003 .{ }^{8}$ Different from all the existing dihydropyridine calcium antagonists having two methyl groups located at the 2- and 6-positions of the dihydropyridine ring, azelnidipine has an amino group displacing the methyl group at the 2-position. ${ }^{9}$ In addition, azelnidipine has two enantiomers (R-(-)- and $\mathrm{S}-(+)$-enantiomers) due to an asymmetric carbon at the 4-position, and the (R)-(-) enantiomer of dihydropyridine calcium antagonists is considered to possess intrinsic pharmacological activity. ${ }^{10}$

The antihypertensive effect of azelnidipine is primarily based on the inhibition of trans-membrane $\mathrm{Ca}^{2+}$ influx through the voltage-dependent channels of vascular smooth muscles. $\mathrm{Ca}^{2+}$ channels are classified into several subtypes, including L-type, T-type, N-type, P/Q-type, and R-type $\mathrm{Ca}^{2+}$ channels based on their electrophysiological properties. ${ }^{11}$ Azelnidipine is selective for L-type $\mathrm{Ca}^{2+}$ channels. Azelnidipine has strong lipophilicity and affinity to membranes of vascular smooth muscle cells. ${ }^{12}$ A preclinical study showed that azelnidipine could not be removed from the blood vessels, even by washing. ${ }^{13}$ It is retained in the vascular wall after clearance from the blood and continues to elicit a hypotensive effect. Unlike other dihydropyridine CCBs, azelnidipine does not induce reflex tachycardia, probably since it elicits a gradual fall in BP. In addition, clinical studies have demonstrated that azelnidipine significantly reduced heart rate and proteinuria in hypertensive patients by suppressing sympathetic nerve activity. ${ }^{14,15}$ Azelnidipine has also been confirmed to have cardio-protective, cerebro-protective, and anti-atherosclerotic effects, and improves insulin resistance. ${ }^{16}$

Azelnidipine is used in the treatment of patients with hypertension, and the recommended dosage is $8-16 \mathrm{mg}$ orally once daily. ${ }^{17}$ Oral administration of azelnidipine shows rapid, dose-dependent absorption. A series of research was conducted to investigate the pharmacokinetics of different dosages of azelnidipine in healthy Chinese volunteers (Table 1). ${ }^{18-24}$ After a single-dose oral administration of azelnidipine 8-16 mg in 106 healthy Chinese volunteers, peak plasma concentration $\left(\mathrm{C}_{\max }\right)$ was $1.66-23.06 \mathrm{ng} / \mathrm{mL}$, time to $\mathrm{C}_{\max }\left(\mathrm{T}_{\max }\right)$ was $2.6-4.0$ hours, and the area under the plasma concentration versus (vs) time curve from time 0 hour to 96 hours $\left(\mathrm{AUC}_{0-96}\right)$ was $17.9-429 \mathrm{ng} / \mathrm{mL} \cdot \mathrm{h}$. After administration of azelnidipine $8 \mathrm{mg}$ /day for 5-8 days, mean $\mathrm{C}_{\max }$ and $\mathrm{AUC}_{0-96}$ values were 2.63-6.62 ng/mL and 43.8-113.0 ng/mL·h; $\mathrm{T}_{\max }$ was $2.8-3.5$ hours. Steady-state plasma concentration of azelnidipine was achieved after day two. After a single, oral dose of 8-16 mg in healthy Chinese subjects, azelnidipine had an elimination half-life $\left(\mathrm{t}_{1 / 2 \beta}\right)$ of 16.0-28.0 hours. At steady state, the $t_{1 / 2 \beta}$ was 25.2-32.5 hours after administration of azelnidipine $8 \mathrm{mg} /$ day for 5-8 days. Following a single oral dose (4 mg) of ${ }^{14} \mathrm{C}$-labeled azelnidipine in humans, approximately $26 \%$ of total radioactivity was excreted in urine and $63 \%$ in feces over the 7 days post-dosing.

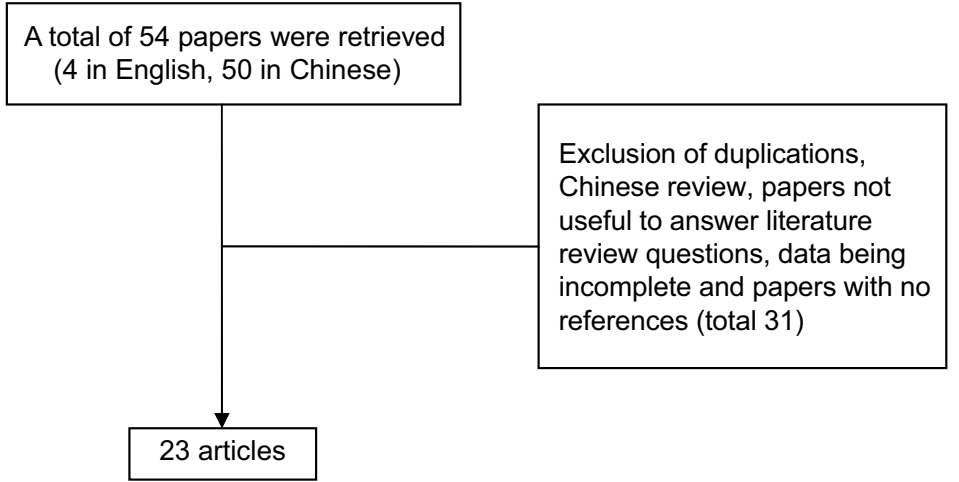

Figure I Flow chart for literature screening. 
Table I Pharmacokinetics parameters of single and multiple dosing azelnidipine respectively by oral administration in Chinese healthy volunteers

\begin{tabular}{|c|c|c|c|c|c|c|c|}
\hline Year of publication & $\begin{array}{l}\text { Number of healthy } \\
\text { volunteers }\end{array}$ & Dose (mg) & Period (d) & $C_{\max }(n g / m L)$ & $\mathbf{T}_{\max }(\mathbf{h})$ & $t_{1 / 2 \beta}(h)$ & $\mathrm{AUC}_{0-96}(\mathrm{ng} / \mathrm{mL} \cdot \mathrm{h})$ \\
\hline \multicolumn{8}{|c|}{ A single dose of azelnidipine $(8 \mathrm{mg})$} \\
\hline $2008^{18}$ & 12 & 8 & I & $5.13 \pm 2.20$ & $2.9 \pm 1.4$ & $25.0 \pm 4.3$ & $53.6 \pm 17.1$ \\
\hline $2008^{19}$ & 8 & 8 & I & $8.66 \pm 1.15$ & $2.8 \pm 1.2$ & $22.8 \pm 2.4$ & $186.0 \pm 47.0$ \\
\hline $2008^{20}$ & 5 & 8 & I & $5.85 \pm 3.27$ & $3.0 \pm 1.4$ & $16.0 \pm 5.5$ & $89.6 \pm 37.3$ \\
\hline $201 I^{21}$ & 10 & 8 & I & $1.66 \pm 0.45$ & $3.5 \pm 1.1$ & $21.3 \pm 8.1$ & $17.9 \pm 6.0$ \\
\hline $2011^{22}$ & 10 & 8 & 1 & $4.16 \pm 1.86$ & $2.6 \pm 0.6$ & $23.0 \pm 6.8$ & $44.1 \pm 19.6$ \\
\hline $2012^{24}$ & 8 & 8 & 1 & $5.91 \pm 2.83$ & $3.3 \pm 1.3$ & $20.3 \pm 7.6$ & $61.1 \pm 33.8$ \\
\hline \multicolumn{8}{|c|}{ A single dose of azelnidipine $(16 \mathrm{mg})$} \\
\hline $2008^{18}$ & 12 & 16 & I & $9.48 \pm 3.70$ & $2.6 \pm 0.8$ & $24.6 \pm 5.6$ & $107.9 \pm 39.1$ \\
\hline $2008^{19}$ & 8 & 16 & I & $19.17 \pm 4.13$ & $3.0 \pm 0.9$ & $23.5 \pm 4.2$ & $429.0 \pm 145.0$ \\
\hline $2008^{20}$ & 5 & 16 & I & $23.06 \pm 5.63$ & $2.6 \pm 1.0$ & $18.0 \pm 1.9$ & $272.5 \pm 128.4$ \\
\hline $2011^{21}$ & 10 & 16 & I & $4.25 \pm 1.38$ & $4.0 \pm 1.2$ & $19.5 \pm 4.0$ & $49.9 \pm 17.5$ \\
\hline $2011^{22}$ & 10 & 16 & I & $10.60 \pm 5.40$ & $2.7 \pm 0.6$ & $25.2 \pm 13.8$ & $80.5 \pm 50.4$ \\
\hline $2012^{24}$ & 12 & 16 & I & $10.61 \pm 3.93$ & $3.7 \pm 1.0$ & $28.0 \pm 7.7$ & $139.5 \pm 72.9$ \\
\hline \multicolumn{8}{|c|}{ Multiple dose of azelnidipine $(8 \mathrm{mg} / \mathrm{d})$} \\
\hline $2008^{18}$ & 12 & 8 & 8 & $6.12 \pm 2.27$ & $3.1 \pm 1.1$ & $25.2 \pm 5.0$ & $53.6 \pm 18.4$ \\
\hline $201 I^{21}$ & 10 & 8 & 5 & $2.63 \pm \mathrm{I} .4 \mathrm{I}$ & $3.5 \pm 1.1$ & $32.5 \pm 9.2$ & $43.8 \pm 26.4$ \\
\hline $201 I^{22}$ & 10 & 8 & 7 & $6.62 \pm 2.23$ & $2.8 \pm 0.9$ & $25.5 \pm 9.5$ & $113.0 \pm 67.0$ \\
\hline $2012^{24}$ & 6 & 8 & 7 & $5.88 \pm 1.90$ & $3.2 \pm 0.7$ & $28.2 \pm 8.0$ & $86.7 \pm 41.6$ \\
\hline
\end{tabular}

Abbreviations: $\mathrm{C}_{\max }$, peak plasma concentration; $\mathrm{T}_{\max }$, time to peak plasma concentration; $\mathrm{t}_{1 / 22}$, elimination half-life; $A \mathrm{AU}_{0-96}$, area under the plasma concentration versus time curve from time $0 \mathrm{~h}$ to $96 \mathrm{~h}$; d, days; h, hours.

The pharmacokinetics of azelnidipine in patients with hypertension appeared to be similar to those of healthy volunteers. ${ }^{17}$ The influence of food on azelnidipine was studied on healthy Japanese volunteers. When a single oral dose $(10 \mathrm{mg})$ of azelnidipine was administered after a meal, the mean $\mathrm{C}_{\max }$ was 2.6-fold higher when compared with the values obtained in the fasted state $(18.5 \mathrm{vs} 7.1 \mathrm{ng} / \mathrm{mL}$, $P<0.05$ ), while mean $\mathrm{AUC}_{\infty}, \mathrm{T}_{\max }$, and $\mathrm{t}_{1 / 2 \beta}$ values not statistically different between after-meal and the fasted state. As a result, administration of azelnidipine after a meal is recommended by the manufacturer. ${ }^{17}$ Azelnidipine is extensively bound to human plasma proteins $(90 \%-91 \%)$. Like most CCBs, azelnidipine undergoes extensive first-pass hepatic metabolism. ${ }^{17}$ Azelnidipine is metabolized by cytochrome P450 (CYP) 3A4 in the liver and has no active metabolite. It has the potential for interactions with other drugs or compounds that are substrates for this enzyme. A study was conducted about azelnidipine $(8 \mathrm{mg})$ administrated with itraconazole $(50 \mathrm{mg})$, a drug with a strong CYP3A4 inhibitory activity. $\mathrm{C}_{\max }$ and $\mathrm{AUC}_{12 \mathrm{~h}}$ values of azelnidipine administrated with itraconazole were 1.6 and 2.8 times higher than those with azelnidipine alone. ${ }^{17}$ In hypertensive patients with renal dysfunction, the steady-state plasma concentrations of azelnidipine were approximately 2 -fold higher than those in healthy volunteers $(P<0.01) .{ }^{17}$

\section{Efficacy studies of azelnidipine in Chinese patients}

A number of clinical trials in Chinese patients have demonstrated that azelnidipine was effective for treatment of hypertension. Azelnidipine 8-16 mg administered once daily in the morning for 2 months significantly reduced BP over 24 hours in 60 young patients with essential hypertension $(P<0.05)$, as demonstrated with 24-hour ABPM. The loading rate of BP was significantly lower after treatment with azelnidipine $(P<0.01) .{ }^{25}$ Twenty-seven patients with mild-to-moderate hypertension (mean SBP/DBP 158.2/98.6 $\mathrm{mmHg}$ ) received azelnidipine $16 \mathrm{mg} /$ day for 12 weeks, and BP was significantly decreased (mean SBP/DBP 124.5/80.2 $\mathrm{mmHg}$ at the end of the study, $P<0.05) .^{26}$

Furthermore, a series of clinical trials (most of them published in Chinese magazines) have demonstrated that azelnidipine produced a significant reduction in BP in Chinese patients with essential hypertension when compared with other effective anti-hypertensive drugs such as amlodipine, zofenopril, and nifedipine (extended release) $)^{27-39}$ (Table 2). In these studies, azelnidipine $8-16 \mathrm{mg}$ /day was as effective as amlodipine $5-10 \mathrm{mg} /$ day in reducing $\mathrm{BP}$ in primary hypertension. Amlodipine is a widely used calcium antagonist and is known to have a slow and persistent hypotensive effect. A double-blind control study was planned to divide 61 patients 


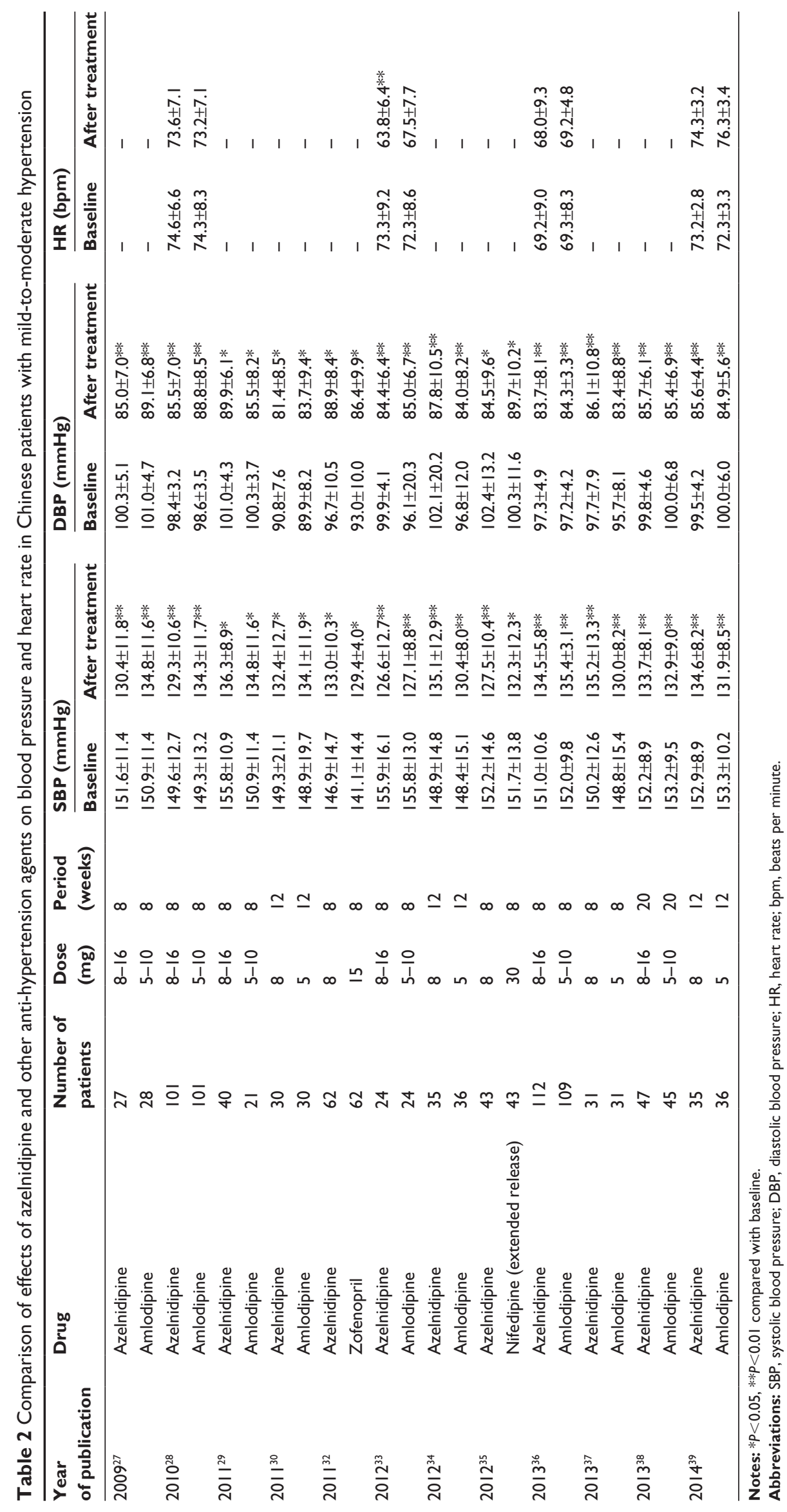


into two groups in which one received azelnidipine 8-16 mg or amlodipine 5-10 mg once daily for a period of 8 weeks. The SBP and DBP decreased significantly in both azelnidipine group and amlodipine group at 2 weeks, 4 weeks, 6 weeks, and 8 weeks after the treatment $(P<0.05)$. The SBP and DBP between the azelnidipine group and the amlodipine group had no significant difference $(P>0.05)$ at all time-points. ${ }^{29}$ In another multicenter, double-blind, randomized study in 231 patients with mild-to-moderate essential hypertension, after azelnidipine $8-16 \mathrm{mg}$ or amlodipine 5-10 $\mathrm{mg}$ once daily for 8 weeks, the DBP of the patients at sitting position in both groups was lower than that at their baseline after 8 weeks of treatment $(13.56 \pm 6.22 \mathrm{mmHg}$ vs $12.94 \pm 5.50 \mathrm{mmHg})$. No significant differences were observed in the two groups. ${ }^{36}$ In studies assessed by ABPM, azelnidipine and amlodipine also showed a comparable 24 hour anti-hypertensive effect. ${ }^{30,37}$

Although the anti-hypertensive effect of azelnidipine is similar to that of amlodipine, azelnidipine has its own advantages. In 76 Chinese patients with mild-to-moderate essential hypertension, the administration of azelnidipine 8-16 mg or amlodipine 5-10 mg once daily for 8 weeks significantly decreased SBP and DBP and the indexes of 24-hour ABPM when compared with those at baseline, and no significant differences were observed in the two groups. In this study, the number of patients with normal dipper circadian rhythm $\mathrm{BP}$ after treatment was higher in the azelnidipine group when compared with that in the amlodipine group. ${ }^{39}$ Meanwhile, azelnidipine has a comparable anti-hypertension effect to angiotensin-converting enzyme inhibitor. Azelnidipine 8-16 mg/day for 8 weeks controlled 24 hour BP (assessed by ABPM) to a similar extent as zofenopril $15-30 \mathrm{mg} /$ day in a randomized and double-blind study in 130 patients with mild-to-moderate hypertension. There were no significant differences between these two groups with regard to the 24-hour BP control. ${ }^{32}$ The anti-hypertension effect of azelnidipine is also superior to second generation of dihydropyridine calcium antagonist. After the administration of azelnidipine ( $8 \mathrm{mg} /$ day) or extended release nifedipine (30 mg/day) for 8 weeks, patients had a significant decrease in SBP and DBP $(P<0.05)$. Meanwhile, the decline of SBP and DBP was significantly greater in the azelnidipine group than those in the extended release nifedipine group. ${ }^{35}$

In addition to its antihypertensive effect, azelnidipine also features other cardiovascular protective effects. Previous studies have demonstrated that azelnidipine, unlike other dihydropyridine CCBs, did not increase, but probably decreased, heart rate in clinical settings. In a clinical trial, 27 hypertensive patients complicated with tachycardia were treated with azelnidipine $16 \mathrm{mg} /$ day for 12 weeks. After the treatment, the heart rate declined from $106.7 \pm 18.7$ beats a minute to $86.3 \pm 19.1$ beats a minute $(P<0.05) .{ }^{26}$ In a randomized controlled study among 48 patients with essential hypertension, administration of azelnidipine (8-16 $\mathrm{mg}$ /day once daily for 8 weeks) significantly decreased the heart rate. However, patients who received amlodipine (5-10 mg/day once daily for 8 weeks) did not have significantly decreased heart rate after the treatment. ${ }^{33}$ Azelnidipine can also prevent left ventricular remodeling and improve systolic and diastolic function. Ninety-two patients with mild-to-moderate essential hypertension were administered azelnidipine $8-16 \mathrm{mg}$ or amlodipine 5-10 mg once daily for 5 months. The left ventricular diastolic function was improved in both groups after the treatment. Compared with that in the amlodipine group, the plasma level of brain natriuretic peptide (BNP) was significantly lower in the azelnidipine group $(P<0.05) .{ }^{38}$ Recent research has also demonstrated that azelnidipine has anti-atherosclerotic properties. ${ }^{17}$ Azelnidipine $8-16 \mathrm{mg}$ once daily for 8 weeks significantly increased brachial-ankle pulse wave velocity in hypertensive patients. ${ }^{39}$ The brachial-ankle pulse wave velocity is an index of arterial stiffness and wave reflection. As a result, azelnidipine achieved significant improvements in arterial stiffness. As for other possible mechanisms, azelnidipine has been reported to elicit anti-atherosclerotic effects by anti-oxidative action. In a clinical trial, 24 patients with hypertension received azelnidipine 8-16 mg once daily for 8 weeks. After the treatment the plasma SOD (an antioxidant enzyme) was significantly increased $(P<0.05)$ when compared with that at baseline. ${ }^{33}$ In this study, azelnidipine also significantly decreased plasma HsCRP $(P<0.05)$ concentration and increased 6-keto-PGF1 $\alpha$ level to inhibit the formation and development of atherosclerosis. In addition, some previous literature has reported that azelnidipine featured reno-protective, improving insulin resistance, and cerebro-protective effects. ${ }^{16}$ However there is no relevant research in Chinese.

\section{Safety and tolerability in use of azelnidipine in Chinese patients}

There are 14 clinical studies published in Chinese (Table 3). ${ }^{25-27,29-39}$ Patients were all diagnosed with essential hypertension and most had mild-to-moderate hypertension. Patients included women and men, the young and the older. Most of the follow-up periods were 8 weeks and the longest was 5 months. No severe adverse events were observed, and nobody dropped out of the therapy because of the adverse events. The most common adverse events were dizziness, 
Table 3 Safety and tolerability in use of azelnidipine in Chinese patients with hypertension

\begin{tabular}{|c|c|c|c|c|c|}
\hline Year of publication & Number of patients & Degree of hypertension & Dose (mg) & Period & Adverse events and number \\
\hline $2009^{27}$ & 27 & Mild-to-moderate & $8-16$ & 8 weeks & $\begin{array}{l}\text { Dizzy I, palpitation I, nausea I, } \\
\text { ankle edema I, depression I }\end{array}$ \\
\hline $2010^{26}$ & 24 & Mild-to-moderate & 16 & 12 weeks & Nausea, tiredness without number \\
\hline $2011^{29}$ & 40 & Mild-to-moderate & 8 & 8 weeks & Headache I, flush 2 \\
\hline $2011^{30}$ & 30 & Mild-to-moderate & 8 & 12 weeks & None reported \\
\hline $2011^{31}$ & 27 & Mild-to-moderate & $8-16$ & 8 weeks & None reported \\
\hline $2011^{32}$ & 62 & Mild-to-moderate & 8 & 8 weeks & Headache 4 , flush 4 \\
\hline $2012^{33}$ & 48 & Mild-to-moderate & $8-16$ & 8 weeks & $\begin{array}{l}\text { Dizzy } 2 \text {, headache I, toothache I, } \\
\text { constipation I, oppression in chest I }\end{array}$ \\
\hline $2012^{34}$ & 38 & Mild-to-moderate & 8 & 12 weeks & None reported \\
\hline $2012^{35}$ & 43 & Mild-to-moderate & 8 & 8 weeks & $\begin{array}{l}\text { Dizzy 2, palpitation } 3 \text {, nausea } 4 \text {, } \\
\text { edema } 2 \text {, arthralgia I }\end{array}$ \\
\hline $2013^{25}$ & 60 & Mild-to-severe & $8-16$ & 2 months & Palpitation 2, flush I \\
\hline $2013^{36}$ & 116 & Mild-to-moderate & $8-16$ & 8 weeks & $\begin{array}{l}\text { Dizzy and headache } 8 \text {, lower limbs } \\
\text { edema I }\end{array}$ \\
\hline $2013^{37}$ & 32 & Mild-to-moderate & 8 & 8 weeks & None reported \\
\hline $2013^{38}$ & 47 & Mild-to-moderate & $8-16$ & 5 months & None reported \\
\hline $2014^{39}$ & 38 & Mild-to-moderate & 8 & 8 weeks & None reported \\
\hline
\end{tabular}

headache, and edema. CCB-related edema is a side effect that may reduce patient compliance or cause necessary switch to another drug. Among these clinical studies, four cases of CCB-related edema occurred in total after treatment with azelnidipine (one ankle edema, one leg edema, two sites without explanation). In studies about comparison of azelnidipine and amlodipine, two patients in the azelnidipine group complained about edema (one ankle edema, one leg edema). Meanwhile, two patients in the amlodipine group suffered from CCB-related edema (one leg edema, one palpebral edema). ${ }^{27,33,36,38}$ When compared with extended release nifedipine, two patients in the azelnidipine group and one patient in the extended release nifedipine group were reported to suffer from edema (both were "site unknown"). ${ }^{35}$ So, the difference of edema incidence rate between azelnidipine and other CCBs needs further investigation.

There is one clinical study published in English about azelnidipine at a dosage of 8-16 $\mathrm{mg}$ compared with amlodipine at a dosage of 2.5-5 mg for 8 weeks in 202 Chinese patients diagnosed with mild-to-moderate essential hypertension. The adverse events (defined as mild-to-moderate) occurred in eight (7.3\%) subjects in the azelnidipine group and eleven (10.0\%) subjects in the amlodipine group $(P=0.485)$. No severe adverse events were observed. Headaches occurred at an incidence rate of $1.82 \%$ vs $4.55 \%$, and dizziness at $2.73 \%$ vs $2.73 \%$, respectively, both the azelnidipine and the amlodipine group. With regard to laboratory data, no great changes were found in serum glucose, uric acid, electrolyte, creatinine, and urea nitrogen in either group. There were no significant changes in pulse rate in either group. ${ }^{28}$

\section{Patient-focused perspectives such as quality of life, patient satisfaction/ acceptability, adherence, and uptake}

Hypertension is a common public health problem in the People's Republic of China, and it is recognized as a lifestyle disease and greatly affects the quality of life of patients. With the change from the biomedical mode to the biologicalsocial-psychological medical model, more and more studies have analyzed the relationship between hypertension and health-related quality of life (HRQL) in Chinese patients with hypertension. ${ }^{40-44}$ These researchers often used the SF-36 table ${ }^{45}$ to assess the HRQL and have demonstrated that individuals with hypertension have a lower score of physical functioning, role-physical, bodily pain, general health, vitality, social functioning, role-emotional, and mental health than normotensive individuals. In perspective of hypertensive patients, the number of symptoms had a great negative impact on HRQL. The sources of symptoms might be the perceived symptoms related to hypertension or the side effects from antihypertensive medication. ${ }^{44}$ Previous studies also reported that increasing comorbidity, including cerebrovascular disorder, ischemic heart disease, and renal disorder, influenced subjects with hypertension in rating their HRQL.$^{43}$ In addition, some socio-demographic factors including sex, age, educational level, region of residence, marital status, frequency of activities, family monthly income, occupations, attitudes toward hypertension, and knowledge of hypertension influenced HRQL of patients with hypertension..$^{40,41,43,44}$ Successful control of BP can improve the quality of life of hypertensive 
patients. ${ }^{44}$ Poor drug adherence is a major contributor to poor BP control. ${ }^{46}$ A number of studies evaluated the adherence levels of antihypertensive pharmacotherapies among the Chinese population. These studies have reported that almost $29.7 \%-53.8 \%$ of patients had good adherence to antihypertensive agents in Chinese mainland. ${ }^{47-49}$ The percentage of patients with good adherence (approximately 65.1\%-86.8\%) was higher in patients in Hong Kong, People's Republic of China. ${ }^{50-52}$ Some researchers also have investigated the factors associated with antihypertensive drug adherence. Among Chinese patients with hypertension, low income, side effects of antihypertensive drugs, dosing frequency, complex medication regimens, bad behavioral factors, lack of knowledge of hypertension and the treatment, employment status, and a selfperceived health status of "poor" were recognized to contribute to antihypertensive drug discontinuation. ${ }^{48,50,52}$ In addition, poor doctor-patient relationship and lack of social support were also associated with poor adherence to antihypertensive agents. ${ }^{46,53}$ Users of $\beta$-receptor blockers were significantly more likely to have their drugs discontinued than users of $\mathrm{CCB}$ in both male and female patients. ${ }^{51}$ However, patients of an older age, female sex, and longer duration of antihypertensive agents used (over 10 years) were reported to have better adherence. ${ }^{52,54}$ Previous literature has also proposed methods to improve medication adherence, such as reinforcement of HBPM, formulating a proper treatment plan, strengthening patients' individualized health education, sending reminders about appointments and continued compliance to medications, making good use of the social support system, organizing health care to provide easy access to health professionals, and building a good doctor-patient relationship. ${ }^{52,53}$ In this way, more patients with hypertension can achieve successful BP control and good quality of life.

\section{Conclusion (place in therapy)}

In this review, we addressed the management issues in the treatment of hypertension in Chinese patients and especially emphasized the DHP-CCB azelnidipine, including the pharmacology, pharmacokinetics, and a series of clinical studies of azelnidipine in a Chinese population. From the current data, azelnidipine has shown to be as effective in lowering high BP and as safe alternative antihypertensive drugs. Especially, this drug could lower tachycardia in patients. During clinical practice we should focus on national or regional people characteristics and evidence-based medical research in a Chinese population, so as to better arrange individualized treatment in patients with hypertension.

\section{Disclosure}

The authors have no conflicts of interest to disclose.

\section{References}

1. Liu LS, Writing Group of 2010 Chinese Guidelines for the Management of Hypertension. [2010 Chinese guidelines for the management of hypertension]. Zhonghua Xin Xue Guan Bing Za Zhi. 2011;39(7):579-615. Chinese.

2. Redon J, Mancia G, Sleight P, et al. Safety and efficacy of low blood pressures among patients with diabetes: subgroup analyses from the ONTARGET (ONgoing Telmisartan Alone and in combination with Ramipril Global Endpoint Trial). J Am Coll Cardiol. 2012;59(1): 74-83.

3. Hansson L, Zanchetti A, Carruthers SG, et al. Effects of intensive blood-pressure lowering and low-dose aspirin in patients with hypertension: principal results of the Hypertension Optimal Treatment (HOT) randomised trial. HOT Study Group. Lancet. 1998;351(9118): $1755-1762$.

4. Messerli FH, Mancia G, Conti CR, et al. Dogma disputed: can aggressively lowering blood pressure in hypertensive patients with coronary artery disease be dangerous? Ann Intern Med. 2006;144(12): 884-893.

5. Sarnak MJ, Greene T, Wang X, et al. The effect of a lower target blood pressure on the progression of kidney disease: long-term follow-up of the modification of diet in renal disease study. Ann Intern Med. 2005;142(5): 342-351.

6. Appel LJ, Wright JJ, Greene T, et al. Intensive blood-pressure control in hypertensive chronic kidney disease. $N$ Engl J Med. 2010;363(10): 918-929.

7. Upadhyay A, Earley A, Haynes SM, Uhlig K. Systematic review: blood pressure target in chronic kidney disease and proteinuria as an effect modifier. Ann Intern Med. 2011;154(8):541-548.

8. No authors listed. Azelnidipine. CS 905, Calblock, RS 9054. Drugs R D. 2003;4(2):122-125.

9. Kawabata K, Urasaki Y. Simultaneous determination of azelnidipine and two metabolites in human plasma using liquid chromatography-tandem mass spectrometry. J Chromatogr B Analyt Technol Biomed Life Sci. 2006;844(1):45-52.

10. Kawabata K, Samata N, Urasaki Y, et al. Enantioselective determination of azelnidipine in human plasma using liquid chromatography-tandem mass spectrometry. J Chromatogr B Analyt Technol Biomed Life Sci. 2007;852(1-2):389-397.

11. Catterall WA, Perez-Reyes E, Snutch TP, Striessnig J. International Union of Pharmacology. XLVIII. Nomenclature and structure-function relationships of voltage-gated calcium channels. Pharmacol Rev. 2005; 57(4):411-425.

12. Nakano K, Egashira K, Tada H, et al. A third-generation, long-acting, dihydropyridine calcium antagonist, azelnidipine, attenuates stentassociated neointimal formation in non-human primates. $J$ Hypertens. 2006;24(9):1881-1889.

13. Oizumi K, Nishino H, Koike H, Sada T, Miyamoto M, Kimura T. Antihypertensive effects of CS-905, a novel dihydropyridine Ca++ channel blocker. Jpn J Pharmacol. 1989;51(1):57-64.

14. Nakamura T, Sugaya T, Kawagoe Y, et al. Azelnidipine reduces urinary protein excretion and urinary liver-type fatty acid binding protein in patients with hypertensive chronic kidney disease. Am J Med Sci. 2007;333(6):321-326.

15. Yamagishi T. Efficacy of azelnidipine on home blood pressure and pulse rate in patients with essential hypertension: comparison with amlodipine. Hypertens Res. 2006;29(10):767-773.

16. Kario K, Sato Y, Shirayama M, et al. Inhibitory effects of azelnidipine tablets on morning hypertension. Drugs R D. 2013;13(1):63-73.

17. Wellington K, Scott LJ. Azelnidipine. Drugs. 2003;63(23): 2613-2624. 
18. Li L, Ding L, Ma PC. [Study on Pharmacokinetics of Azelnidipine in Healthy Volunteers]. Zhongguo Yao Xue Za Zhi. 2008;43(13):1008-1011. Chinese.

19. Zou JJ, Ji HJ, Zhou XH, et al. Determination of azelnidipine by LCESI-MS and its application to a pharmacokinetic study in healthy Chinese volunteers. Pharmazie. 2008;63(8):568-570.

20. Liang YG, Gao HZ, Hu JC, Liu ZY. [Pharmacokinetics of azelnidipine in healthy volunteers]. Zhongguo Lin Chuang Yao Li Xue Za Zhi. 2008;24(4):323-325. Chinese.

21. Zhong SJ, Shi AM, Hua WY, Huan M, Zhang QY. [Pharmacokinetic Study of Azelnidipine Tablets in Healthy Volunteers]. Zhongguo Yao Fang. 2011;22(18):1672-1674. Chinese.

22. Chen Y, Lin Y, Li J, et al. [Study on Pharmacokinetics of Azelnidipine Tablets in Chinese Healthy Volunteers]. Zhongguo Yao Fang. 2011; 22(38):3585-3588. Chinese.

23. Shentu J, Fu L, Zhou H, et al. Determination of amlodipine in human plasma using automated online solid-phase extraction HPLC-tandem mass spectrometry: application to a bioequivalence study of Chinese volunteers. J Pharm Biomed Anal. 2012;70:614-618.

24. Shu CR, Wei LL, Ge MM. [Study on Pharmacokinetics of Azelnidipine Tablet in Healthy Volunteers]. Zhongguo Yao Fang. 2012;23(10):896-898. Chinese.

25. Li H, Li XH. [Evaluation of Therapeutic Efficacy of Azelnidipine for Essential Hypertension in the Youth by Ambulatory Blood Pressure Monitoring]. Zhongguo Yao Fang. 2013;24(36):116-117. Chinese.

26. Qi BH. [Effect of Azelnidipine on high blood pressure complicated with tachycardia]. Hainan Yi Xue Yuan Xue Bao. 2010;16(6):716-717. Chinese.

27. Peng L, Zhao XS, Ma Z, Zhang HY. [The influence of amlodipine and azelnidipine on serum levels of hs-CRP and TIMP-1 of hypertensive patients]. Beijing Yi Xue. 2009;31(8):461-464. Chinese.

28. Zhao X, Wu F, Jia S, et al. Azelnidipine and amlodipine: a comparison of their effects and safety in a randomized double-blinded clinical trial in Chinese essential hypertensive patients. Clin Exp Hypertens 2010;32(6):372-376.

29. Wen YP. [Clinical Observation of Azelnidipine on Mild to Moderate Hypertension]. Guangxi Yi Xue. 2011;33(1):23-26. Chinese.

30. Zheng JL. [Effects of azelnidipine and amlodipine on mid-to-moderate essential hypertension in the older with dynamic blood pressure]. Hebei Yi Yao. 2011;33(20):3092-3094. Chinese.

31. Zhang H, Peng L, Zhao XS. [AntihyPertensive comparison of amlodipine and azelnidipine for mild to moderate essential hypertension]. Zhongguo Xin Xue Guan Za Zhi. 2011;16(4):277-279. Chinese.

32. Wen YP, Huang RJ. [Effects of azelnidipine and zofenopril on ambulatory blood pressure in patients with hypertension]. Guangxi Yi Xue. 2011;33(10):1291-1293. Chinese.

33. Jiao HX, Zhang MQ, Zhao JY, Chen XS. [Evaluation on curative effect of azelnidipine on hypertension and its inhibitory effect on atherosclerosis]. Jilin Da Xue Xue Bao (Yi Xue Ban). 2012;38(4):736-740. Chinese.

34. Huang RJ, Zheng YX, He ML. [Effects of azelnidipine and amlodipine on artery stiffness and dynamic pulse pressure in patients with essential hypertension]. Shi Yong Yi Xue Za Zhi. 2012;28(15):2588-2590. Chinese.

35. Zhao K. [Study on effect of azelnidipine plus atorvastatin in hypertension patients with coronary artery disease]. Hai Xia Yao Xue. 2012;24(11):146-147. Chinese.

36. Li DD, Dong W, Chen YD. [Azelnidipine in treatment of mild-moderate essential hypertension: A clinical trial]. Jie Fang Jun Yi Xue Yuan Xue Bao. 2013;34(9):977-980. Chinese.
37. Li YY, Chen WS, Yu F. [Evaluating azelnidipine and amlodipine treatment in mild-to-moderate primary hypertension with ambulatory blood pressure monitoring system]. Lin Chuang He Li Yong Yao Za Zhi. 2013; 6(6):116-117. Chinese.

38. Yi SX, Wu ZZ, Shao N, Wang YB, Feng WF. [The influence of azelnidipine on left ventricular diastolic function in hypertensive patients]. Xian Dai Zhong Xi Yi Jie He Za Zhi. 2013;22(25):2797-2798. Chinese.

39. Huang RJ, Zheng YX, He ML. [Effects of Azelnidipine and amlodipine on circadian rhythm of blood pressure and atherosclerosis in patients with mild-to-moderate essential hypertension]. Guangxi Yi Ke Da Xue Xиe Bao. 2014;31(01):89-92. Chinese.

40. Wang J, Kang D, Hong Q. [Health-related quality of life in hypertensive patients]. Zhonghua Yi Xue Za Zhi. 1999;79(8):599-602. Chinese.

41. Li W, Liu L, Puente JG, et al. Hypertension and health-related quality of life: an epidemiological study in patients attending hospital clinics in China. J Hypertens. 2005;23(9):1667-1676.

42. Chen Y, Wang SY, Chi GB, Yu XH, Hong C, Li AR. [Evaluation of quality of life of hypertensive patients]. Di Yi Jun Yi Da Xue Xue Bao. 2005;25(11):1387-1389. Chinese.

43. Wang R, Zhao Y, He X, et al. Impact of hypertension on health-related quality of life in a population-based study in Shanghai, China. Public Health. 2009;123(8):534-539.

44. Qian Y, Zhang J, Lin Y, et al. A tailored target intervention on influence factors of quality of life in Chinese patients with hypertension. Clin Exp Hypertens. 2009;31(1):71-82.

45. Lawrence WF, Fryback DG, Martin PA, Klein R, Klein BE. Health status and hypertension: a population-based study. J Clin Epidemiol. 1996; 49(11):1239-1245.

46. Ma C, Chen S, Zhou Y, Huang C. Treatment adherence of Chinese patients with hypertension: a longitudinal study. Appl Nurs Res. 2013;26(4):225-231.

47. Yang GQ. [Medication adherence and its associated factors in patients with essential hypertension]. Zhongguo Yi Yao Zhi Nan. 2009;7(7):40-41. Chinese.

48. Cao ZX, Xing AJ, Liu YQ, Shi JH, Wu SL. [Factors associated with antihypertensive drug compliance in patients with essential hypertension]. Zhonghua Gao Xue Ya Za Zhi. 2009;17(9):843-844. Chinese.

49. Ren H, Sheng XC, Zhang H, Luo HP, Xu J, Fu H. [A study on relationship between compliance with anti-hypertension therapy and assessment of quality of health care in patients with hypertension in community]. Zhonghua Yu Fang Yi Xue Za Zhi. 2014;48(5):345-349. Chinese.

50. Wong MC, Jiang JY, Griffiths SM. Factors associated with antihypertensive drug compliance in 83,884 Chinese patients: a cohort study. J Epidemiol Community Health. 2010;64(10):895-901.

51. Wong MC, Jiang JY, Gibbs T, Griffiths SM. Factors associated with antihypertensive drug discontinuation among Chinese patients: a cohort study. Am J Hypertens. 2009;22(7):802-810.

52. Lee GK, Wang HH, Liu KQ, Cheung Y, Morisky DE, Wong MC Determinants of medication adherence to antihypertensive medications among a Chinese population using Morisky Medication Adherence Scale. PLoS One. 2013;8(4):e62775.

53. Wang W, Yan F, Xue CY, Zhang X, Li ZH. [Factors Influencing Patients' Compliance with Hypertension Management in the Community: Qualitative Research Synthesis]. Zhongguo Xun Zheng Yi Xue Za Zhi. 2010;10(4):429-432. Chinese.

54. Wang W, Lau Y, Loo A, Chow A, Thompson DR. Medication adherence and its associated factors among Chinese community-dwelling older adults with hypertension. Heart Lung. 2014;43(4):278-283. 


\section{Publish your work in this journal}

Therapeutics and Clinical Risk Management is an international, peerreviewed journal of clinical therapeutics and risk management, focusing on concise rapid reporting of clinical studies in all therapeutic areas, outcomes, safety, and programs for the effective, safe, and sustained use of medicines. This journal is indexed on PubMed Central, CAS,

EMBase, Scopus and the Elsevier Bibliographic databases. The manuscript management system is completely online and includes a very quick and fair peer-review system, which is all easy to use. Visit http://www.dovepress.com/testimonials.php to read real quotes from published authors.

Submit your manuscript here: http://www.dovepress.com/therapeutics-and-clinical-risk-management-journal 